\title{
Recovery Method of Pyrolytic Carbon Surface after Exposure to Chlorine Trifluoride Gas
}

\author{
Masaya Hayashi', Keisuke Kurashima', Hitoshi Habuka1, Akio Ishiguro ${ }^{2}$, Shigeaki Ishii², \\ Yoshiaki Daigo ${ }^{2}$, Hideki Ito' ${ }^{2}$ Ichiro Mizushima ${ }^{2}$, Yoshinao Takahashi ${ }^{3}$ \\ ${ }^{1}$ Yokohama National University, Hodogaya, Yokohama, Japan \\ ${ }^{2}$ NuFlare Technology, Inc., Yokohama, Japan \\ ${ }^{3}$ KANTO DENKA KOGYO CO., LTD., Marunouchi Chiyoda, Tokyo, Japan \\ Email: habuka-hitoshi-ng@ynu.ac.jp
}

How to cite this paper: Hayashi, M., Kurashima, K., Habuka, H., Ishiguro, A., Ishii, S., Daigo, Y., Ito, H., Mizushima, I. and Takahashi, Y. (2021) Recovery Method of Pyrolytic Carbon Surface after Exposure to Chlorine Trifluoride Gas. Advances in Chemical Engineering and Science, 11, 65-76. https://doi.org/10.4236/aces.2021.111005

Received: November 28, 2020

Accepted: January 12, 2021

Published: January 15, 2021

Copyright $\odot 2021$ by author(s) and Scientific Research Publishing Inc. This work is licensed under the Creative Commons Attribution International License (CC BY 4.0).

http://creativecommons.org/licenses/by/4.0/

\begin{abstract}
An annealing process was developed for the practical recover of a purified pyrolytic carbon (PPyC) surface from damage, such as color change and peeling, due to fluorination during exposure to chlorine trifluoride gas at high temperatures for the cleaning of a silicon carbide chemical vapor deposition reactor. The PPyC surface was annealed at $900^{\circ} \mathrm{C}$ for $10 \mathrm{~min}$ in ambient nitrogen containing oxygen at the concentrations of $0.01 \%-20 \%$. The rainbow-like colored surface returned to the dark gray color of the original PPyC. Simultaneously, the thin peeled films disappeared. The Raman spectra showed that the PPyC surface chemical bonding returned to that of the original one. The oxygen concentration as low as $0.01 \%$ could recover the PPyC surface along with reducing the surface pit formation, when the combination of the exposure to chlorine trifluoride gas and the recovery was repeated.
\end{abstract}

\section{Keywords}

Pyrolytic Carbon, Recovery, Chlorine Trifluoride, Fluorine Out-Diffusion, Annealing

\section{Introduction}

Carbon materials [1] are significantly useful for various applications. In industry, the pyrolytic carbon materials are used in the corrosive and high temperature environments. Typically, they are utilized in a chemical vapor deposition (CVD) reactor which uses highly corrosive gases, such as hydrogen chloride and chlorine trifluoride gases. For this purpose, the useful material is purified pyrolytic carbon (PPyC) which is produced by the pyrolysis of hydrocarbon precursors and an- 
nealing [2] [3]. The PPyC has been evaluated as the silicon carbide CVD susceptor coating film [4]-[10], because it was shown to be resistant to the chlorine trifluoride $\left(\mathrm{ClF}_{3}\right)$ gas which was an effective silicon carbide CVD reactor cleaning gas.

By using the chlorine trifluoride gas, the PPyC film often suffers from fluorination to a depth of about $700 \mathrm{~nm}$ that causes damage, such as a color change into the rainbow-like one and a thin layer peeling from the PPyC surface [7] [8] [9]. Thus, any methods for recovering the PPyC surface should be studied. Because the graphite surface was reported to be recovered by annealing in ambient nitrogen and in that containing oxygen [9], the practical recovery method for the damaged PPyC should be developed for enabling the recycling of the PPyC-coated parts.

In this study, the recovery method of the PPyC was thus studied in detail utilizing the annealing. After the PPyC surface was exposed to the chlorine trifluoride gas, it was annealed in ambient nitrogen at various temperatures and various oxygen concentrations. The surface morphology and the Raman spectra were evaluated to show that the $\mathrm{PPyC}$ had recovered.

\section{Experimental Procedure}

The sample, as shown in Figure 1(b), was a high-purity carbon plate $(3 \mathrm{~cm}$ wide $\times 3 \mathrm{~cm}$ long $\times 1 \mathrm{~mm}$ thick), the surface of which was coated with a PPyC film (40- $\mu \mathrm{m}$-thick, IG-110PyC+U, Toyo Tanso Co., Ltd., Tokyo, Japan) [2]. The original PPyC-coated surface had a dark gray color with a pebble-like morphology [7] [8] [9] [10].

Figure 1(a) shows the reactor used in this study. In the quartz chamber, the sample was exposed to the chlorine trifluoride gas and annealed in ambient nitrogen. Infrared light emitted from halogen lamps heated the sample.

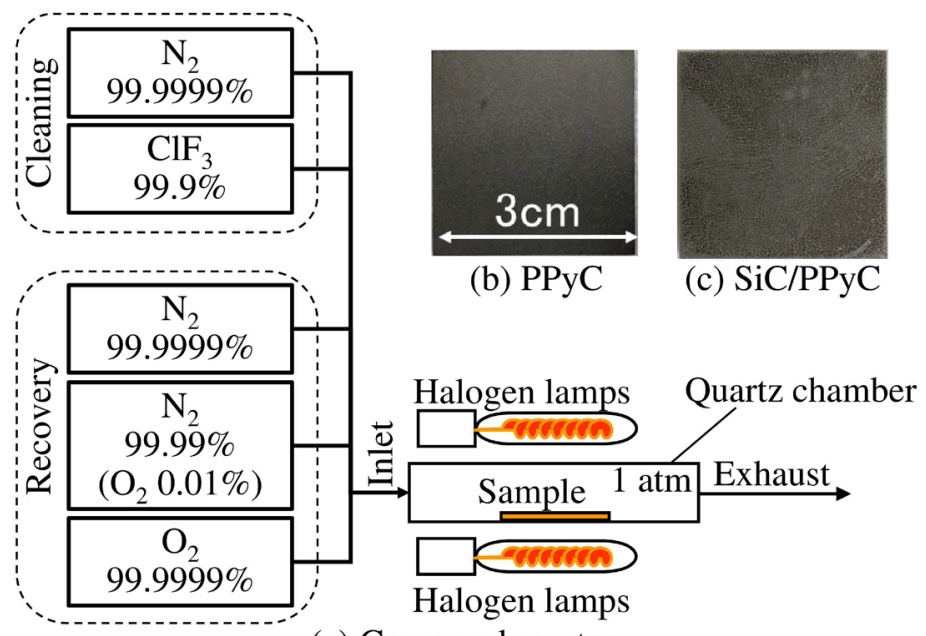

(a) Gases and reactor

Figure 1. Reactor and samples in this study. (a) Gases and reactor for exposing samples to chlorine trifluoride gas and for annealing in ambient nitrogen containing oxygen, (b) PPyC plate and (c) silicon carbide film deposited on PPyC plate. 
Figure 2 shows the overall process and conditions in this study. A particle-type $30-\mu \mathrm{m}$-thick silicon carbide film, as shown in Figure 1 (c), was formed on the PPyC-coated plate using the EPIREVO ${ }^{\mathrm{rm}} \mathrm{S} 6$ reactor (NuFlare Technology, Inc., Yokohama, Japan), an industrial scale high-speed rotation vertical flow CVD reactor. The film thickness was measured by a micrometer. The silicon carbide layer was removed by the cleaning. For the cleaning, the sample was exposed to $5 \%$ and $100 \%$ chlorine trifluoride gases at atmospheric pressure and at temperatures higher than $500^{\circ} \mathrm{C}$ for $10 \mathrm{~min}$. The following exothermic chemical reaction was assumed to occur between the chlorine trifluoride gas and silicon carbide [1] [4]-[10].

$$
3 \mathrm{SiC}+8 \mathrm{ClF}_{3} \rightarrow 3 \mathrm{SiF}_{4}+3 \mathrm{CF}_{4}+4 \mathrm{Cl}_{2}
$$

Due to the cleaning, the PPyC surface color was often changed to a rainbow-like one along with peeling of the significantly thin film. For the recovery, the PPyC surface was annealed in ambient nitrogen at $600^{\circ} \mathrm{C}, 900^{\circ} \mathrm{C}$ and $1200^{\circ} \mathrm{C}$ and atmospheric pressure for $10 \mathrm{~min}$. When the effect of the annealing condition was focused on, the bare PPyC surface having no silicon carbide film was exposed to the chlorine trifluoride gas.

The surface morphology of the samples was observed by scanning electron microscopy (SEM) (VE-8800, Keyence, Tokyo). The surface chemical bonding condition was evaluated by Raman spectroscopy (inVia Reflex, Renishaw K. K., Tokyo).

\section{Results and Discussion}

\subsection{Annealing Temperature}

The annealing temperature was evaluated in ambient nitrogen containing $20 \%$

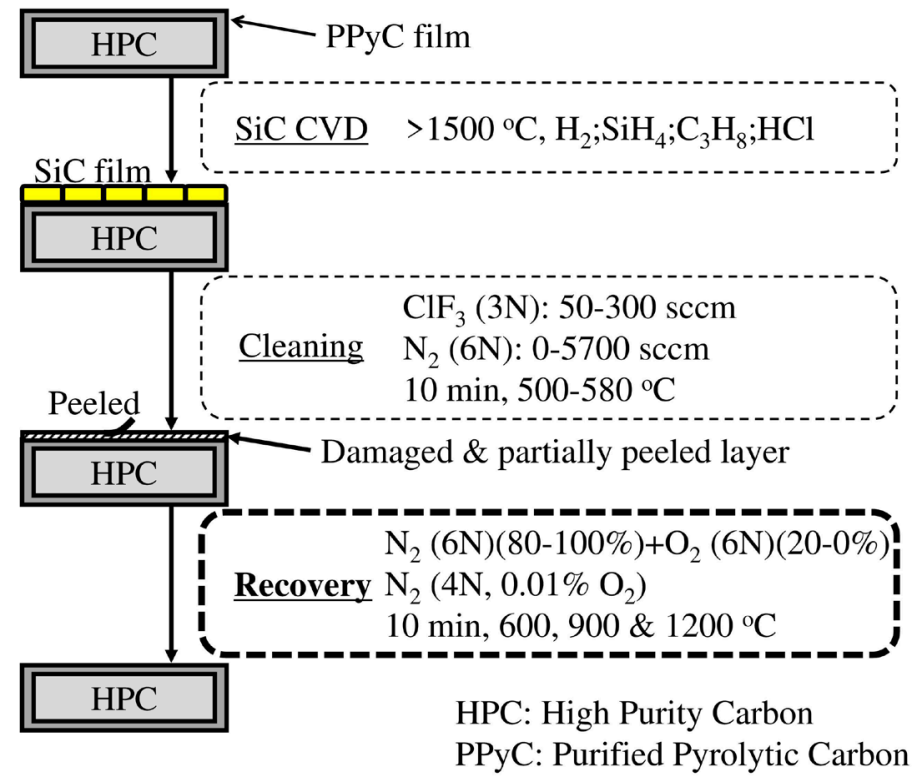

Figure 2. Process and typical conditions for silicon carbide deposition, cleaning by chlorine trifluoride and annealing in ambient nitrogen containing oxygen. 
oxygen. Figure 3 shows that the surface appearance changed along with the cleaning and the recovery when the sample had no silicon carbide film. The sample surface changed its appearance by exposure to the $100 \%$ chlorine trifluoride gas at $570^{\circ} \mathrm{C}-580^{\circ} \mathrm{C}$ from a gray color to rainbow-like colors, as indicated by the letter R in Figures 3(a1)-(c1). The sample surface had partially peeled as indicated by the letter $\mathrm{P}$ in Figure 3(a1), Figure 3(b1) and Figure 3(c1).

These samples were annealed at $600^{\circ} \mathrm{C}, 900^{\circ} \mathrm{C}$ and $1200^{\circ} \mathrm{C}$. After the annealing at $600^{\circ} \mathrm{C}$, the faint rainbow-like color remained as indicated by the letter $\mathrm{R}$ in Figure 3(a2). Additionally, a very small amount of the peeled thin films still remained, as indicated by the letter $\mathrm{P}$. The annealing temperature of $600^{\circ} \mathrm{C}$ was concluded to be too low.

Next, the temperature of $1200^{\circ} \mathrm{C}$ was evaluated, as shown in Figure $3(\mathrm{c} 1)$ and Figure 3(c2). Figure 3(c1) shows that overall surface showed a rainbow-like color, as indicated by the letter $\mathrm{R}$. The center region contained the peeled film as indicated by the letter $\mathrm{P}$. The damaged appearance disappeared after the annealing at $1200^{\circ} \mathrm{C}$, as shown in Figure 3(c2). In addition, at the right bottom edge, a small white-colored region was newly produced, as indicated by the letter $\mathrm{W}$. This region was considered to be formed due to the loss of the PPyC film by the significant oxidation at the very high temperature, while the mechanism should be experimentally verified. Thus, the annealing temperature of $1200^{\circ} \mathrm{C}$ was considered to be too high.

By the recovery at $900^{\circ} \mathrm{C}$, the rainbow-like colored and peeled region as indicated by R \& P in Figure 3(b1) was perfectly changed to the dark colored surface without any peeled film, as shown in Figure 3(b2). Based on Figure 3, the annealing temperature of $900^{\circ} \mathrm{C}$ was considered to be optimum.



Figure 3. Surface appearance by cleaning and recovery at (a) $600^{\circ} \mathrm{C}$, (b) $900^{\circ} \mathrm{C}$ and (c) $1200^{\circ} \mathrm{C}$. R: rainbow-like colored region, P: peeled film, and W: white-colored region. 
The sample surface after the annealing at $900^{\circ} \mathrm{C}$ was evaluated in detail. Figure 4 shows the Raman spectra of sample surface which was annealed in ambient nitrogen containing $20 \%$ oxygen at $900^{\circ} \mathrm{C}$ for $10 \mathrm{~min}$. In this figure, the G-band was greater than the D-band. The ratio of the D-band to G-band, $\mathrm{R}$, was 0.5. While this value was higher than the $\mathrm{R}$ value of the original PPyC surface of about 0.2 [9], it was comparable to that which had no color change after exposure to the chlorine trifluoride gas. Because the color-changed surface empirically had the $\mathrm{R}$ values higher than 1, the sample shown in Figure 3(b2) was considered to be significantly recovered from that shown in Figure 3(b1).

Figure 5 shows the surface morphology of the sample shown in Figure 3(b2). Figure 5(a) shows a small and shallow pebble-like morphology. Figure 5(b) is the magnified image of Figure 5(a). There were small pits, the diameters of which were about $0.03 \mathrm{~mm}$. This might be caused by the oxidation that occurred at the significantly damaged spots. Thus, the optimum oxygen concentration might be lower than $20 \%$ for suppressing the pit formation.

\subsection{Oxygen Concentration}

The oxygen concentration was reduced from $20 \%$ to $5 \%$ at the fixed temperature of $900^{\circ} \mathrm{C}$. Figure 6 (a) shows the sample surface after the exposure to the $100 \%$

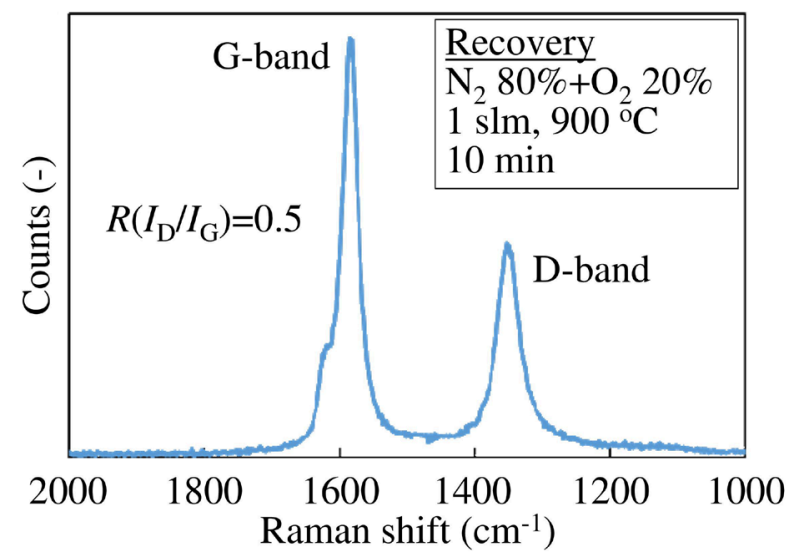

Figure 4. Raman spectra of PPyC surface shown in Figure 3(b2).

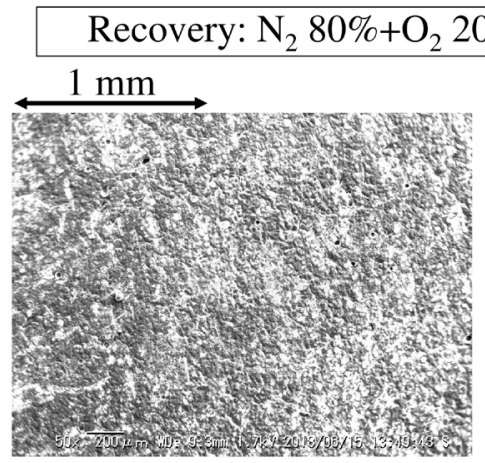

(a)

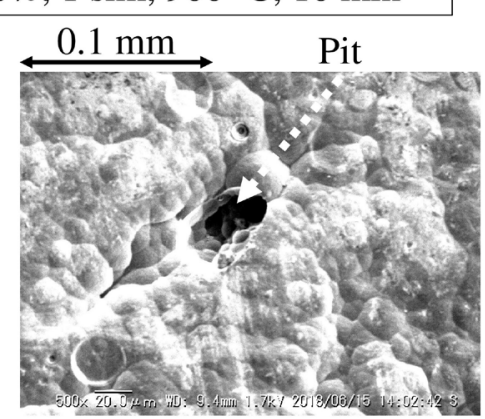

(b)

Figure 5. Surface morphology of sample shown in Figure 3(b2). 


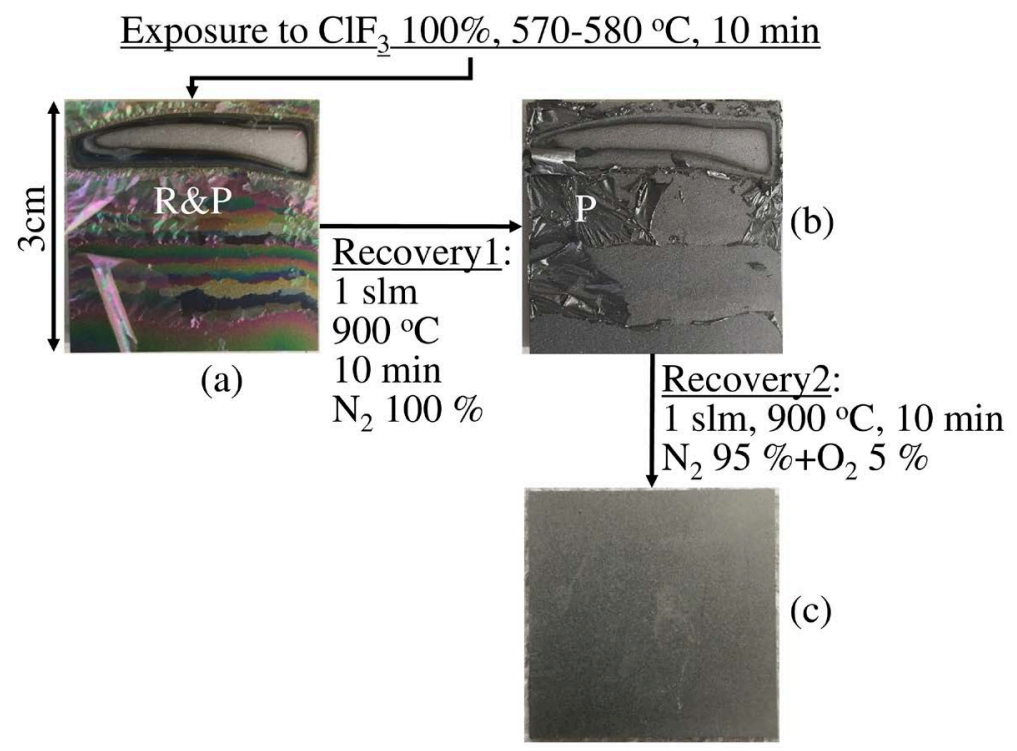

Figure 6. Sample appearance along with exposure to chlorine trifluoride gas and recovery in ambient nitrogen at $900^{\circ} \mathrm{C}$. (a) after exposure to chlorine trifluoride gas at $570^{\circ} \mathrm{C}$ $580^{\circ} \mathrm{C}$, (b) after annealing in ambient nitrogen without oxygen and (c) after annealing in ambient nitrogen containing 5\% oxygen. R: rainbow-like colored region and P: peeled film.

chlorine trifluoride gas at $570^{\circ} \mathrm{C}-580^{\circ} \mathrm{C}$ for $10 \mathrm{~min}$. The overall surface showed the rainbow-like color.

Additionally, most of the surface had peeled, as indicated by the letters R\&P. For confirming the role of the nitrogen gas, the surface was first annealed at $900^{\circ} \mathrm{C}$ in ambient nitrogen without adding oxygen. Figure $6(\mathrm{~b})$ shows that the surface still contained the peeled films, while the color returned from the rainbow-like one to the gray one similar to the original PPyC. Thus, the ambient nitrogen was concluded to recover the color by fluorine out-diffusion [7] [8]. However, because the peeled films could not be removed, the use of oxygen was shown to be necessary. Next, the sample was annealed at $900^{\circ} \mathrm{C}$ in the ambient nitrogen containing 5\% oxygen. As shown in Figure $6(\mathrm{c})$, the peeled films did not remain.

Figure 7 shows the appearance of PPyC surface along with the recovery process using $5 \%$ oxygen. Figure 7 (a) shows the surface after the exposure to the chlorine trifluoride gas at $570^{\circ} \mathrm{C}-580^{\circ} \mathrm{C}$ for $10 \mathrm{~min}$. The surface showed the rainbow-like color, as indicated by the letter $\mathrm{R}$. The sample was annealed in ambient nitrogen containing 5\% oxygen. The surface had the dark gray appearance as shown in Figure 7(b). Figure 7(c) is a magnified image of Figure 7(b). The pebble-like morphology being the same as the original PPyC surface was confirmed. When the surface was observed in detail, small pits having diameters of several $\mu \mathrm{m}$ could be found. While the pit diameter shrank from that at the oxygen concentration of $20 \%$, it should further reduce.

The surface chemical bonding condition was evaluated by the Raman spectra, as shown in Figure 8. The G-band is clear and intense, while the D-band is 




(a)

(b)

(c)

Figure 7. Sample appearance along with cleaning and recovery at $900^{\circ} \mathrm{C}$. (a) after cleaning by chlorine trifluoride gas at $500^{\circ} \mathrm{C}$, (b) after annealing in ambient nitrogen containing $5 \%$ oxygen. (c) is magnified image of (b). R: rainbow-like colored region.

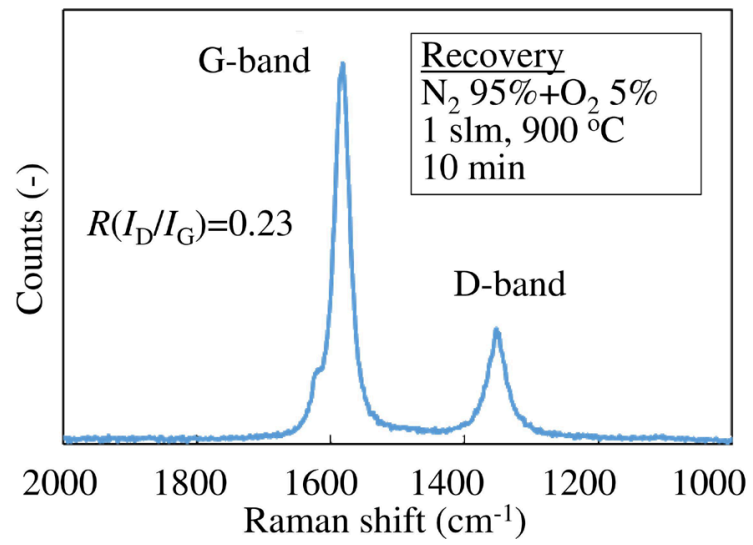

Figure 8. Raman spectra of PPyC surface shown in Figure 7(c).

weak. The $\mathrm{R}$ value is 0.23 which is comparable to that of the original PPyC surface. Thus, the ambient nitrogen containing $5 \%$ oxygen is concluded to be appropriate for recovering the carbon bonding of the PPyC.

By annealing in ambient nitrogen containing 5\% oxygen, the chemical bonding was considered to be sufficiently recovered, while small pits were produced. The oxygen at the significantly low concentrations is expected to suppress the pit formation for recovering the PPyC surface.

\subsection{Repetition of Cleaning and Recovery}

The annealing in ambient nitrogen containing the oxygen at the significantly low concentration of $0.01 \%$ was evaluated. Simultaneously, the moderate cleaning condition was used. For this evaluation, a $30-\mu \mathrm{m}$ thick silicon carbide film was formed on the PPyC surface.

Figure 9 shows the surface appearance of the PPyC along with three repetitions of cleaning and recovery. The cleaning at $500^{\circ} \mathrm{C}$ used $5 \%$ chlorine trifluoride gas in ambient nitrogen for reducing the damage of the PPyC surface by means of reducing the exothermic reaction heat [9]. Next, the PPyC surface was recovered by annealing at $900^{\circ} \mathrm{C}$ in ambient nitrogen containing $0.01 \%$ oxygen. 


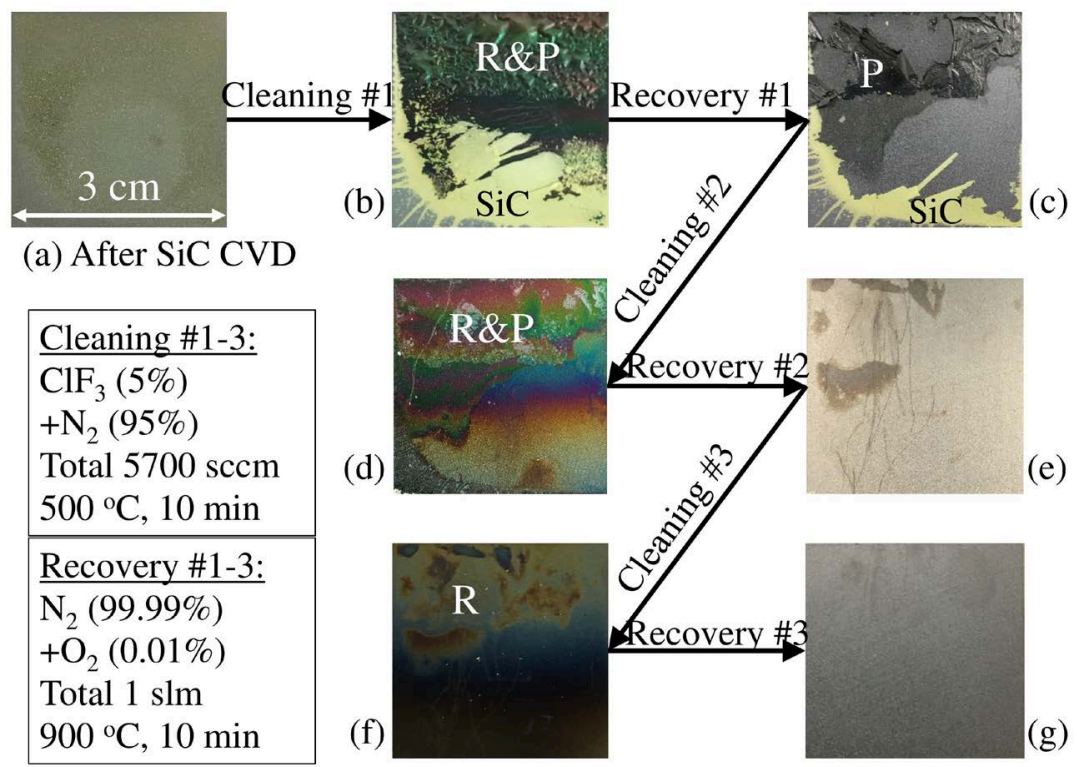

Figure 9. Surface appearance along with three repetitions of cleaning using $5 \%$ chlorine trifluoride gas and $500^{\circ} \mathrm{C}$ and recovery by annealing at $900^{\circ} \mathrm{C}$ in ambient nitrogen containing $0.01 \%$ oxygen. R: rainbow-like colored region and P: peeled film.

The sample having the silicon carbide film, as shown in Figure 9(a), was cleaned by the Cleaning \#1. While more than half of the silicon carbide film was removed, the silicon carbide film remained as shown by the yellow-colored region, in the lower portion of Figure 9(b). Figure 9(b) simultaneously shows that the upper half of the sample was peeled having the rainbow-like color, as indicated by the letters $\mathrm{R} \& \mathrm{P}$. The peeling situation in this figure was comparable to those shown in Figure 3(b1) and Figure 6(a). The sample was then annealed in ambient nitrogen containing $0.01 \%$ oxygen by the Recovery \#1. Figure 9(c) shows the appearance after the Recovery \#1. Most of the sample surface showed a gray color, not the rainbow-like one; it had bright and dark contrasting regions. The surface showed the peeling in a small area. The sample surface additionally had some silicon carbide film remaining along the bottom edge.

For removing the silicon carbide film, the Cleaning \#2 was performed. As shown in Figure 9(d), the overall sample surface showed the rainbow-like color with little peeling, as indicated by the letters $\mathrm{R} \& \mathrm{P}$. The silicon carbide film was considered to be mostly removed. By using the Recovery \#2, the rainbow-like color changed to the gray color, as shown in Figure 9(e). In Figure 9(e), there coexisted different contrasting regions, dark and bright, which might indicate that a significantly damaged $\mathrm{PPyC}$ region still remained.

The two regions were then observed in detail.

Figure 10 shows an SEM image of the sample surface shown in Figure 9(e). The bright and dark contrasting positions $\mathrm{b}$ and $\mathrm{c}$, respectively, were observed in detail. Figure 10(b) shows that the pebble-like morphology with small white dots existed at position $b$. The Raman spectra of position $b$ showed that the G-band was greater than the D-band, as shown in Figure 11(b). In contrast, the 




(a)



(c)

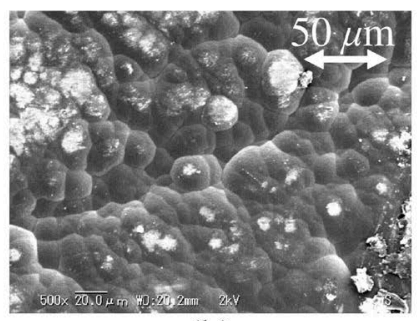

(b)



(d)

Figure 10. SEM images of sample surface (b) at positions b, (c) c and (d) d after Recovery \#2, shown in (a) (same as Figure 9(e)).

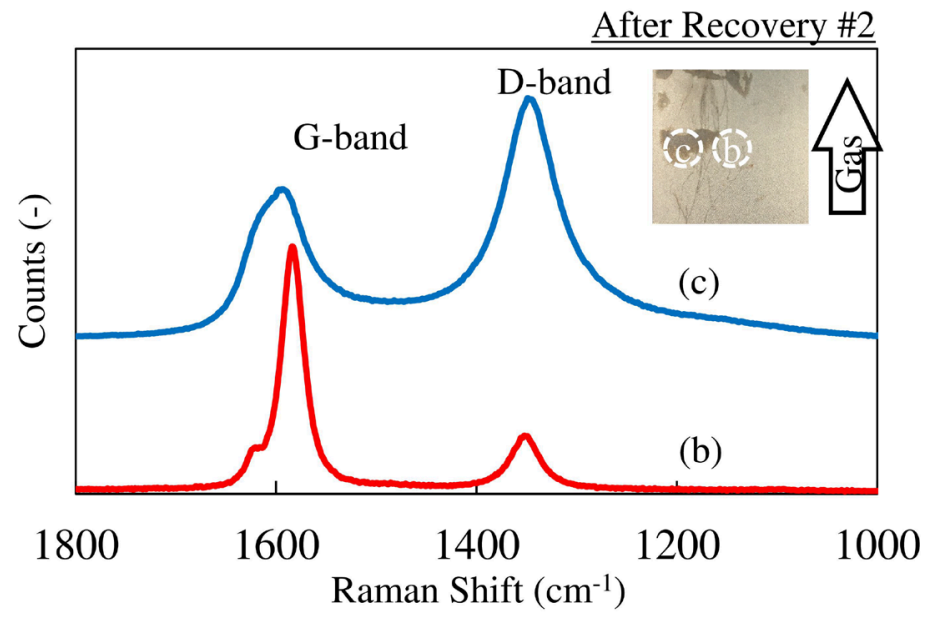

Figure 11. Raman spectra of PPyC surface at positions b and c shown in Figure 9(e).

density of the small dots was high at the dark contrasting position $c$, as shown in Figure 10(c). The Raman spectra at position c showed a strong D-band with a very weak G-band. Thus, the dark contrasting position $c$ had more damage than the bright contrasting position $b$.

At position d in Figure 10(a), a significantly small amount of the silicon carbide film was found to remain, as shown in Figure 10(d). Thus, further cleaning was necessary.

The Cleaning \#3 was performed as shown in Figure 9(f). Because the image of the rainbow-like color in Figure 9(f) was similar to that in Figure 9(d), the surface damage caused by the Cleaning \#3 was considered to be similar to that by the Cleaning \#2. The surface appearance after the Recovery \#3 is shown in Figure $9(\mathrm{~g})$. The overall sample surface uniformly showed the gray color. 
For evaluating the surface condition in detail, SEM images and Raman spectra were obtained. Figures 12(b)-(d) show the surface at positions b, $c$ and d, respectively, in Figure 12(a) which is the same as Figure 9(g). A pebble-like morphology was observed over the entire sample surface along with a significantly small number of white small spots. Based on the detailed observations, the significantly small and shallow pits, less than $5 \mu \mathrm{m}$ in diameter, were detected as shown in Figure 12(d). The pit density was obviously lower than that in Figure 7 (c). Thus, the $0.01 \%$ oxygen was considered to reduce the pit formation.

Figure 13 shows the typical Raman spectra of the sample before and after Recovery \#3. Figure 13(a) and Figure 13(b) show the Raman spectra of Figure 9(f) and Figure 9(g), respectively. In Figure 13(a), the intensities of the G- and D-bands are comparable. After the Recovery \#3, the defect region indicated by

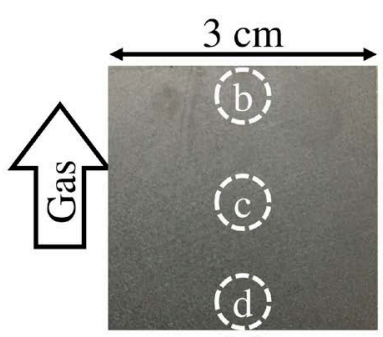

(a)

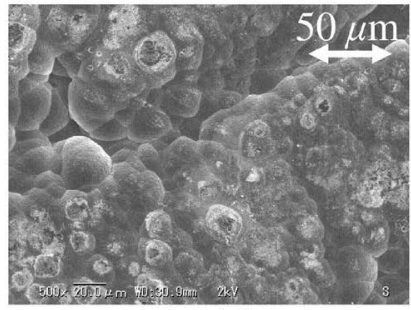

(c)
After Recovery \#3

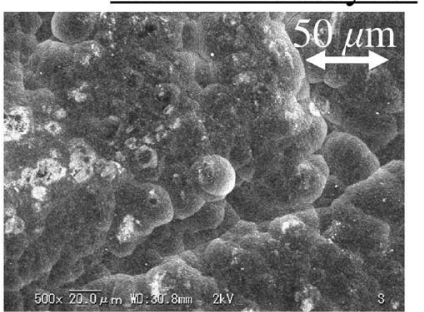

(b)

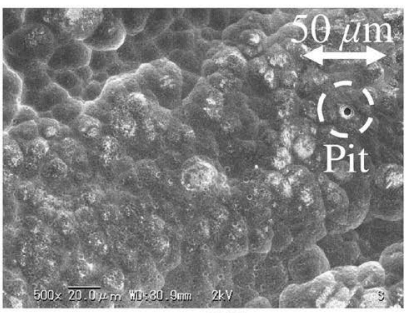

(d)

Figure 12. SEM images of PPyC surface (b) at positions b, (c) c and (d) d shown in (a) (same as Figure 9(g)).



Figure 13. Typical Raman spectra of PPyC surface (a) before and (b) after Recovery \#3, shown in Figure 9(f) and Figure 9(g), respectively. 
the D-band was considered to be removed; the entire spectra resembled that shown in Figure 8. Thus, the sample surface after three repetitions of the cleaning and recovery methods was considered to make the PPyC surface similar to the original PPyC.

\section{Conclusion}

The annealing in ambient nitrogen containing oxygen could recover the $\mathrm{PPyC}$ surface having damage, such as a color change and peeling, caused due to the exposure to the chlorine trifluoride gas at temperatures higher than about $570^{\circ} \mathrm{C}$. The optimum annealing temperature was $900^{\circ} \mathrm{C}$. The oxygen concentration could be as low as $0.01 \%$, when the combination of the cleaning and recovery was repeated. The Raman spectra showed that the chemical bonds at the PPyC surface recovered to that of the original one. The density and size of the small pits at the surface tended to decrease with the decreasing oxygen concentration. The recovering process will enable recycling of the CVD reactor parts made of the PPyC when the CVD reactor cleaning process uses a strong etchant, such as the chlorine trifluoride gas.

\section{Conflicts of Interest}

The authors declare no conflicts of interest regarding the publication of this paper.

\section{References}

[1] Greenwood, N.N. and Earnshaw, A. (1997) Chemistry of the Elements. 2nd Edition, Butterworth-Heinemann, Oxford, UK.

[2] https://www.toyotanso.co.jp/Products/Special graphite/

[3] Reznik, B. and Huttinger, K.J. (2002) On the Terminology for Pyrolytic Carbon, Carbon, 40, 621-624. https://doi.org/10.1016/S0008-6223(01)00282-2

[4] Habuka, H., Fukumoto, Y., Mizuno, K., Ishida, Y. and Ohno, T. (2014) Cleaning Process Applicable to Silicon Carbide Chemical Vapor Deposition Reactor. ECS Journal of Solid State Science and Technology, 3, N3006-N3009.

https://doi.org/10.1149/2.002401jss

[5] Mizuno, K., Habuka, H., Ishida, Y. and Ohno, T. (2015) In Situ Cleaning Process of Silicon Carbide Epitaxial Reactor. ECS Journal of Solid State Science and Technology, 4, 137-140. https://doi.org/10.1149/2.0091505jss

[6] Mizuno, K., Shioda, K., Habuka, H., Ishida, Y. and Ohno, T. (2016) Repetition of in Situ Cleaning Using Chlorine Trifluoride Gas for Silicon Carbide Epitaxial Reactor. ECS Journal of Solid State Science and Technology, 5, 12-15. https://doi.org/10.1149/2.0051602jss

[7] Shioda, K., Habuka, H., Ito, H., Mitani, S. and Takahashi, Y. (2017) Susceptor Coating Materials Applicable for SiC Reactor Cleaning. Materials Science Forum, 897, 99-102. https://doi.org/10.4028/www.scientific.net/MSF.897.99

[8] Shioda, K., Kurashima, K., Habuka, H., Ito, H., Mitani, S. and Takahashi, Y. (2017) Quick Cleaning Process for Silicon Carbide Chemical Vapor Deposition Reactor. ECS Journal of Solid State Science and Technology, 6, 526-530. 
https://doi.org/10.1149/2.0161708jss

[9] Kurashima, K., Hayashi, M., Habuka, H., Ito, H., Mitani, S., Mizushima, I., and Takahashi, Y. (2019) High-Temperature Reactor Cleaning Using Chlorine Trifluoride Gas for Silicon Carbide Chemical Vapor Deposition. ECS Journal of Solid State Science and Technology, 8, 400-406. https://doi.org/10.1149/2.0081908jss

[10] Hayashi, M., Mamyouda, T., Habuka, H., Ishiguro, A., Ishii, S., Daigo, Y., Ito, H., Mizushima, I. and Takahashi, Y. (2020) Process Design of Silicon Carbide Chemical Vapor Deposition Reactor Cleaning Using Chlorine Trifluoride Gas Accounting for Exothermic Reaction Heat. ECS Journal of Solid State Science and Technology 9 , 104008. https://doi.org/10.1149/2162-8777/abc3cf 